\title{
Relationship of Host Genotype to Bipolaris Leaf Blight Severities and Yield Components of Adlay
}

\author{
Seog Won Chang, Northern Agricultural Research Station, Gyeonggido Agricultural Research and Extension Ser- \\ vices, Yonchon 486-833, Korea; and Byung Kook Hwang, Laboratory of Molecular Plant Pathology, College of \\ Life and Environmental Sciences, Korea University, Seoul 136-701, Korea
}

\begin{abstract}
Chang, S. W., and Hwang, B. K. 2002. Relationship of host genotype to Bipolaris leaf blight severities and yield components of adlay. Plant Dis. 86:774-779.

Leaf blight, caused by Bipolaris coicis, is one of the most destructive and major yield-limiting diseases of adlay (Coix lacryma-jobi var. ma-yuen). Adlay is used as an ornamental, and as a medicinal and cereal food in many countries. Field studies performed from 1997 to 1999 in Korea evaluated the resistance of 30 adlay genotypes to Bipolaris coicis and determined the relationship of cultivar resistance to leaf blight development and yield. Adlay response to leaf blight was quantitative rather than qualitative, varying greatly among cultivars or lines tested. Disease severity was lowest in Tsukuba B7, Tsukuba B15, and Muzu, and highest in Huksuk 1, Limgae, and Huksuk 2. Leaf position significantly affected disease severity, with lower leaves being more severely infected than upper leaves. Yield reductions of up to $52.4 \%$ for line Huksuk 2 were observed and were primarily associated with reductions in kernel numbers per plant, thousand kernel weight, and percent kernel ripeness. Loss of yield and yield components by leaf blight were less in resistant line Tsukuba B15 than in susceptible line Huksuk 2.
\end{abstract}

Adlay or Job's tears (Coix lacryma-jobi L. var. ma-yuen (Romanet) Stapf.), native to India, Burma, China, and Malaysia, has been grown extensively in South Asia $(1,18)$. Adlay seeds are used ornamentally, and as a medicinal and cereal food in many countries $(1,18)$. Leaf blight, caused by the fungus Bipolaris coicis (Nisikadoi) (teleomorph: Cochliobolus nisikadoi) Shoemaker, is one of the most destructive and major yield-limiting diseases in adlay production $(2,8,23)$. The pathogen has a wide spectrum of pathogenicity in the graminea family, including adlay, corn, wheat, and barley (9,21). B. coicis infects all major portions of the adlay plant and is present throughout the adlay-growing season. Symptoms incited by B. coicis include seed rot, coleoptile blight, seedling blight, and leaf blight. Leaf blight or seedling blight is observed most frequently in the field $(3,7)$. Symptoms of leaf blight are usually first evident on lower leaves 60 to 70 days after sowing in the field. Leaf blight is extremely severe on adlay plants at the ripening stage. Lesions appear as small spots or leaf-tip blight that are oblong to irregular in shape. These lesions frequently exhibit chlorotic borders. Mature leaf blight lesions are gray to tan in color and are dis-

Corresponding author: B. K. Hwang

E-mail: bkhwang@korea.ac.kr

Accepted for publication 15 February 2002.

Publication no. D-2002-0419-01R

(C) 2002 The American Phytopathological Society tinctly oblong in shape. A distinguishing feature of leaf blight is that lesions typically run parallel to leaf veins. Further lesion expansion results in the coalescing of lesions and the blighting of entire leaves, hence the name leaf blight. However, when infection occurs during later growth stages, leaf blight lesions on adlay leaves appear as small spots or chlorotic, fleck-type lesions $(2,10,13)$. Since the mid1990 s, the prevalence and severity of leaf blight have increased markedly in the northern part of Korea $(2,12)$. The increase in the frequency of leaf blight epidemics has been associated with continuous adlay cultivation and extended periods of high relative humidity and dew. During the Korean adlay growing season, rainfall is frequent and humidity is high from the flowering stage to the ripening stage (5).

Effective measures for controlling leaf blight of adlay include burning or eradicating crop residues, spraying with fungicides, and planting resistant cultivars. It is now common in Korea to rely on fungicides, e.g., difenoconazole (Novartis, East Hanover, NJ), to control adlay leaf blight (12). Complete dependence on fungicides for control of leaf blight in adlay usually is undesirable for adlay growers because of possible fungicide residues in plants, and because of the high cost of fungicides. For this reason, development of adlay cultivars resistant to leaf blight is one of the most effective and environmentally sound means of controlling adlay leaf blight. To better understand how host plant resistance influences leaf blight epidemics and adlay yield, it is essential to know the relation- ship between levels of resistance and development of leaf blight in the field. Also, yield loss estimates based on adlay leaf blight severity would provide growers with valuable information regarding adlay cultivar selection for leaf blight control. This information also would be of value to adlay breeders attempting to incorporate resistance into cultivars.

Yield losses due to severe leaf blight infection can be considerable in seasons favorable for disease development, resulting in reduced grain fill and lodging. While there are no reliable estimates of yield losses caused by adlay leaf blight, relationships between disease severity and yield loss have been measured in other crops. For instance, Large and Doling (11) predicted winter wheat yield losses of 3 and $8 \%$ at mildew severities of 2.5 and $16 \%$, respectively. A wheat yield loss of $33 \%$ was predicted at $100 \%$ severity of powdery mildew (4). In wheat-Pyrenophora triticirepentis combinations, Rees et al. (17) reported about $50 \%$ losses in grain yield of winter wheat from tan spot. Severe tan spot also was found to cause 9 to $20 \%$ reductions in thousand kernel weight in seven of 30 cultivars of spring wheat (20).

The objectives of this study were to evaluate reactions of 30 adlay genotypes to leaf blight in hill plots, and to determine yield loss of adlay associated with epidemic development of leaf blight on six selected adlay genotypes of varying levels of resistance in the field.

\section{MATERIALS AND METHODS}

Hosts. Thirty adlay cultivars or breeding lines were evaluated during 1997 and 1998 in hill plots. Cultivar names and origins are given in Table 1.

Field layout. Field trials were performed at the Northern Agricultural Research Station's (NARS) experimental farm, Gyeonggido Agricultural Research and Extension Services (ARES), Yonchon, Korea, where the environment for leaf blight development is considered favorable. Adlay genotypes were sown in hill plots with 92 seeds per hill on 17 April 1997 and 1998. Hill plots $(60 \times 15 \mathrm{~cm})$, spaced $60 \mathrm{~cm}$ apart, were arranged in a randomized complete block design with three replicates. Fertilizer was applied at rates of 108,60 , and $60 \mathrm{~kg}$ of actual NPK per ha in the forms of $\left(\mathrm{NH}_{4}\right)_{2} \mathrm{SO}_{4}, \mathrm{P}_{2} \mathrm{O}_{5}$, and $\mathrm{K}_{2} \mathrm{O}$, respectively, before sowing. Ad- 
ditional $\mathrm{N}$ fertilizer was applied at 72 $\mathrm{kg} / \mathrm{ha}$ after heading. The field was handweeded and fungicides were not applied. Leaf positions on the culms of 10 plants arbitrarily selected within each hill plot were marked by small plastic clips of different colors. This permitted disease assessments on the identical leaf each time. Leaves on these adlay plants were numbered from 1 to the flag leaf, beginning at the bottom of the plant.

Leaf blight assessment. Disease development was rated on the marked leaves every 7 days from 15 June to 23 September 1997 and from 15 June to 22 September 1998. Means for each leaf position by plot were used in all subsequent analysis. Leaf blight severity was recorded as the visible percentage of leaf area diseased. Disease severity for whole plants was calculated from the leaf blight severities of individual leaves. Leaf blight severities for individual leaves and whole plants were converted to areas under disease progress curve (AUDPC) to compare relative levels of resistance of adlay genotypes. The AUDPC was calculated as described by Shaner and Finney (19):

$$
\mathrm{AUDPC}=\sum_{i=1}^{n}\left(X_{i+1}+X_{i}\right)\left(t_{i+1}-t_{i}\right) / 2
$$

where $X_{i}=$ disease severity (percent diseased leaf area) at the $i$ th observation, $t_{i}=$ time (days) at the $i$ th observation, and $n=$ total number of observations.

Assessment of grain yield and yield components. Based on the 1997 field test data, six adlay genotypes exhibiting a range of reactions to leaf blight were selected from the 30 adlay cultivars or lines originally tested. These were used to evaluate for leaf blight resistance and yield potentials in the field. The adlay lines Tsukuba B15 and Muzu were selected as resistant checks. The cultivars Yulmu 1 and Yonchon had moderate resistance. The lines Limgae and Huksuk 2 were susceptible checks. Heading dates of all adlay genotypes tested are within 2 weeks of each other.

Tests were done at the experimental farm of the NARS, ARES, Yonchon, Korea, during 1998 and 1999. The experimental plots consisted of a healthy control (fungicide sprayed) and a leaf blightinfected (unsprayed) plot arranged in a $2 \times$ 6 factorial design with fungicide treatment as the main-plot factor and cultivar as the subplot factor. Experimental units were replicated three times. Adlay seeds were sown in $6 \times 7 \mathrm{~m}^{2}$ plots with 11 rows and 0.6-m row spacing on 17 April 1998 and 1999. Each plot consisted of approximately 467 plants. Before sowing, all plots were top-dressed with $108 \mathrm{~kg}$ of $\mathrm{N}, 60 \mathrm{~kg}$ of $\mathrm{P}$, and $60 \mathrm{~kg}$ of $\mathrm{K}$ per hectare. Additional $\mathrm{N}$ fertilizer was applied at $72 \mathrm{~kg} / \mathrm{ha}$ after heading. Since natural infection levels were considered sufficient in the experimental plots, artificial inoculation with $B$. coicis was unnecessary. Healthy control plots were completely protected from leaf blight by spraying the fungicide difenoconazole ( $10 \%$ EC, Novartis) every 10 days from just before heading to harvest. Fungicide was applied at the rate of 1.25 $\mathrm{kg}$ in 2,500 liters of water per ha.

Leaf blight severity, recorded as the per- centage of the leaf area diseased over the whole plant, was evaluated every 10 days from 15 June to 10 September 1998 and 1999. Twenty plants per plot were randomly examined for disease severity. Terminal disease severity was evaluated 158 days after sowing. Leaf blight severity data were converted to the AUDPC to compare

Table 1. Disease severity (\% diseased leaf area) and area under disease progress curve (AUDPC) of leaf blight for 30 adlay genotypes in the hill plots in 1997 and 1998 at Yonchon, Korea

\begin{tabular}{|c|c|c|c|c|c|}
\hline \multirow[b]{2}{*}{ Genotype } & \multirow[b]{2}{*}{ Origin } & \multicolumn{2}{|c|}{$\%$ diseased leaf area } & \multicolumn{2}{|c|}{ AUDPC } \\
\hline & & 1997 & 1998 & 1997 & 1998 \\
\hline Huksuk 2 & Japan & $89.4 \mathrm{a}^{\mathrm{z}}$ & $72.1 \mathrm{ab}$ & $609.3 \mathrm{a}$ & $463.7 \mathrm{a}-\mathrm{c}$ \\
\hline Huksuk 1 & Japan & $77.3 \mathrm{bc}$ & $74.0 \mathrm{a}$ & $505.3 \mathrm{~b}$ & $500.6 \mathrm{a}$ \\
\hline Limgae & Korea & $72.4 \mathrm{~b}-\mathrm{d}$ & $65.4 \mathrm{~b}-\mathrm{e}$ & 497.9 bc & $456.4 \mathrm{a}-\mathrm{c}$ \\
\hline Onsan & Korea & 69.0 b-e & $65.7 \mathrm{~b}-\mathrm{e}$ & 494.9 b-d & 439.8 b-d \\
\hline UCN-570 & Korea & 69.6 b-e & $56.6 \mathrm{f}-\mathrm{i}$ & $488.5 \mathrm{~b}-\mathrm{d}$ & $413.5 \mathrm{~d}-\mathrm{g}$ \\
\hline Yulhuk & Korea & $68.6 \mathrm{c}-\mathrm{e}$ & $57.6 \mathrm{f}-\mathrm{i}$ & $479.1 \mathrm{~b}-\mathrm{d}$ & $413.0 \mathrm{~d}-\mathrm{h}$ \\
\hline Huksuk 6 & Japan & $77.6 \mathrm{a}$ & $66.5 \mathrm{~b}-\mathrm{d}$ & $476.2 \mathrm{c}-\mathrm{e}$ & $446.4 \mathrm{c}-\mathrm{f}$ \\
\hline Dongbuk 1 & Japan & $67.7 \mathrm{de}$ & $67.4 \mathrm{f}-\mathrm{i}$ & $474.1 \mathrm{c}-\mathrm{e}$ & $435.3 \mathrm{c}-\mathrm{e}$ \\
\hline TsukubaR46 & Japan & $72.3 \mathrm{~b}-\mathrm{d}$ & $58.7 \mathrm{~b}-\mathrm{d}$ & $473.1 \mathrm{c}-\mathrm{e}$ & $398.2 \mathrm{e}-\mathrm{i}$ \\
\hline Wolin & Korea & $68.3 \mathrm{de}$ & $63.7 \mathrm{bc}$ & $464.6 \mathrm{~d}-\mathrm{f}$ & $454.5 \mathrm{bc}$ \\
\hline Milyang 4 & Korea & $71.5 \mathrm{~b}-\mathrm{d}$ & $65.8 \mathrm{e}-\mathrm{h}$ & $462.5 \mathrm{~d}-\mathrm{g}$ & $486.8 \mathrm{ab}$ \\
\hline Yonchon & Korea & $67.9 \mathrm{de}$ & $60.5 c-f$ & $462.1 \mathrm{~d}-\mathrm{g}$ & $439.4 \mathrm{e}-\mathrm{i}$ \\
\hline UCN-690-11 & Korea & $65.8 \mathrm{~d}-\mathrm{g}$ & $57.2 \mathrm{~b}-\mathrm{e}$ & $448.1 \mathrm{e}-\mathrm{h}$ & $428.0 \mathrm{c}-\mathrm{g}$ \\
\hline Aewon & Japan & $69.5 \mathrm{~b}-\mathrm{e}$ & $61.2 \mathrm{c}-\mathrm{g}$ & $446.7 \mathrm{f}-\mathrm{i}$ & $404.5 \mathrm{e}-\mathrm{i}$ \\
\hline Bokheung & Korea & $60.8 \mathrm{e}-\mathrm{i}$ & $55.9 \mathrm{~g}-\mathrm{i}$ & $436.1 \mathrm{~g}-\mathrm{i}$ & $384.0 \mathrm{~g}-\mathrm{j}$ \\
\hline Yulmu 1 & Korea & $66.7 \mathrm{~d}-\mathrm{f}$ & $59.1 \mathrm{e}-\mathrm{h}$ & $425.3 \mathrm{~h}-\mathrm{j}$ & $405.1 \mathrm{~d}-\mathrm{i}$ \\
\hline Sishin & Korea & $63.8 \mathrm{~d}-\mathrm{h}$ & $54.5 \mathrm{~g}-\mathrm{i}$ & $418.7 \mathrm{ij}$ & $364.0 \mathrm{~h}-\mathrm{j}$ \\
\hline Youngmun & Korea & $61.7 \mathrm{e}-\mathrm{i}$ & $59.3 \mathrm{~d}-\mathrm{h}$ & $416.8 \mathrm{ij}$ & $404.5 \mathrm{~d}-\vec{i}$ \\
\hline Jinwee & Korea & $61.3 \mathrm{e}-\mathrm{i}$ & 59.4 d-h & $409.4 \mathrm{jk}$ & $394.0 \mathrm{e}-\mathrm{i}$ \\
\hline Gaejeong & Korea & $56.9 \mathrm{~g}-\mathrm{j}$ & $53.1 \mathrm{i}-\mathrm{k}$ & $404.5 \mathrm{j}$ & $391.4 \mathrm{e}-\mathrm{i}$ \\
\hline Japan & Japan & $57.6 \mathrm{~g}-\mathrm{j}$ & $57.2 \mathrm{f}-\mathrm{i}$ & $379.4 \mathrm{kl}$ & $392.5 \mathrm{f}-\mathrm{i}$ \\
\hline Youngdong & Korea & $55.7 \mathrm{~h}-\mathrm{j}$ & $61.5 \mathrm{c}-\mathrm{g}$ & $377.6 \mathrm{kl}$ & $410.0 \mathrm{~d}-\mathrm{g}$ \\
\hline Wonduk & Korea & $56.2 \mathrm{~h}-\mathrm{j}$ & $57.4 \mathrm{f}-\mathrm{i}$ & $377.2 \mathrm{kl}$ & $394.6 \mathrm{~d}-\mathrm{i}$ \\
\hline Tsukuba B7 & Japan & $56.8 \mathrm{f}-\mathrm{j}$ & $45.9 \mathrm{jk}$ & $373.3 \mathrm{kl}$ & $295.2 \mathrm{k}-\mathrm{m}$ \\
\hline Muzu 1 & Korea & $53.4 \mathrm{ij}$ & $55.5 \mathrm{~g}-\mathrm{i}$ & 371.01 & $398.2 \mathrm{e}-\mathrm{i}$ \\
\hline Dongbuk 4 & Japan & $57.3 \mathrm{~g}-\mathrm{j}$ & $58.7 \mathrm{~d}-\mathrm{g}$ & $368.0 \mathrm{kl}$ & 396.8 e-i \\
\hline Muzu & Korea & $52.9 \mathrm{ij}$ & $46.1 \mathrm{jk}$ & 366.01 & $326.4 \mathrm{~lm}$ \\
\hline Tsukuba B4 & Japan & $54.6 \mathrm{ij}$ & $52.2 \mathrm{~h}-\mathrm{j}$ & 362.11 & $364.2 \mathrm{~m}$ \\
\hline Ou 1 & Japan & $55.6 \mathrm{~h}-\mathrm{j}$ & $54.4 \mathrm{~g}-\mathrm{i}$ & 355.01 & $348.0 \mathrm{j}-1$ \\
\hline Tsukuba B15 & Japan & $49.2 \mathrm{j}$ & $44.9 \mathrm{k}$ & $328.5 \mathrm{~m}$ & $304.0 \mathrm{i}-\mathrm{k}$ \\
\hline $\mathrm{LSD}_{0.05}$ & & 5.3 & 6.0 & 23.1 & 33.2 \\
\hline
\end{tabular}

y Rated 158 days after sowing.

$\mathrm{z}$ Values in each column with different letters show significant differences at $P=0.05$ according to the Fisher's protected least significant difference (LSD) test. Data are means of three replicates.

Table 2. Area under disease progress curve (AUDPC) for various leaves and whole plants of six adlay genotypes in an evaluation of resistance to Bipolaris coicis in the hill plots sown on 17 April 1997 and 1998 at Yonchon, Korea

\begin{tabular}{lccccc}
\hline & \multicolumn{5}{c}{ AUDPC } \\
\cline { 2 - 6 } Genotype & Leaf 3y & Leaf 6 & Leaf 9 & Flag leaf & Whole plant \\
\hline 1997 & & & & \\
Huksuk 2 & $885.0 \mathrm{a}^{\mathrm{z}}$ & $629.9 \mathrm{a}$ & $327.9 \mathrm{a}$ & $169.1 \mathrm{a}$ & $608.1 \mathrm{a}$ \\
Limgae & $858.4 \mathrm{ab}$ & $544.9 \mathrm{~b}$ & $224.0 \mathrm{~b}$ & $36.1 \mathrm{bc}$ & $497.5 \mathrm{~b}$ \\
Yonchon & $818.4 \mathrm{bc}$ & $496.2 \mathrm{~b}$ & $115.8 \mathrm{c}$ & $27.1 \mathrm{~b}$ & $461.6 \mathrm{bc}$ \\
Yulmu 1 & $771.1 \mathrm{~cd}$ & $398.8 \mathrm{c}$ & $122.3 \mathrm{c}$ & $39.2 \mathrm{a}$ & $427.7 \mathrm{c}$ \\
Muzu & $759.0 \mathrm{~d}$ & $319.3 \mathrm{~d}$ & $98.5 \mathrm{c}$ & $15.0 \mathrm{c}$ & $366.6 \mathrm{~d}$ \\
Tsukuba B15 & $737.2 \mathrm{~d}$ & $278.8 \mathrm{~d}$ & $45.5 \mathrm{~d}$ & $15.2 \mathrm{c}$ & $328.8 \mathrm{~d}$ \\
LSD 0.05 & 30.5 & 39.4 & 18.7 & 9.3 & 22.9 \\
1998 & & & & $27.7 \mathrm{a}$ & $457.2 \mathrm{a}$ \\
Huksuk 2 & $818.7 \mathrm{abc}$ & $400.6 \mathrm{~b}$ & $95.3 \mathrm{bc}$ & $4.8 \mathrm{c}$ & $459.0 \mathrm{a}$ \\
Limgae & $874.8 \mathrm{ab}$ & $508.7 \mathrm{a}$ & $155.0 \mathrm{a}$ & $5.4 \mathrm{c}$ & $389.9 \mathrm{~b}$ \\
Yonchon & $898.0 \mathrm{a}$ & $342.6 \mathrm{~b}$ & $115.7 \mathrm{~b}$ & $10.1 \mathrm{~b}$ & $400.2 \mathrm{ab}$ \\
Yulmu 1 & $780.1 \mathrm{bc}$ & $344.6 \mathrm{~b}$ & $64.9 \mathrm{c}$ & $0.6 \mathrm{~d}$ & $326.3 \mathrm{c}$ \\
Muzu & $799.3 \mathrm{abc}$ & $157.3 \mathrm{c}$ & $24.6 \mathrm{~d}$ & $0.9 \mathrm{~d}$ & $307.6 \mathrm{c}$ \\
Tsukuba B15 & $761.7 \mathrm{c}$ & $111.3 \mathrm{c}$ & $36.8 \mathrm{~d}$ & 2.1 & 35.4 \\
LSD 0.05 & 65.2 & 51.3 & 19.9 & & \\
\hline
\end{tabular}

${ }^{\mathrm{y}}$ Leaves are numbered from 1 to flag leaf, from the ground.

${ }^{\mathrm{z}}$ Values in each column with different letters show significant differences at $P=0.05$ according to the Fisher's protected least significant difference (LSD) test. Data are means of three replicates. 


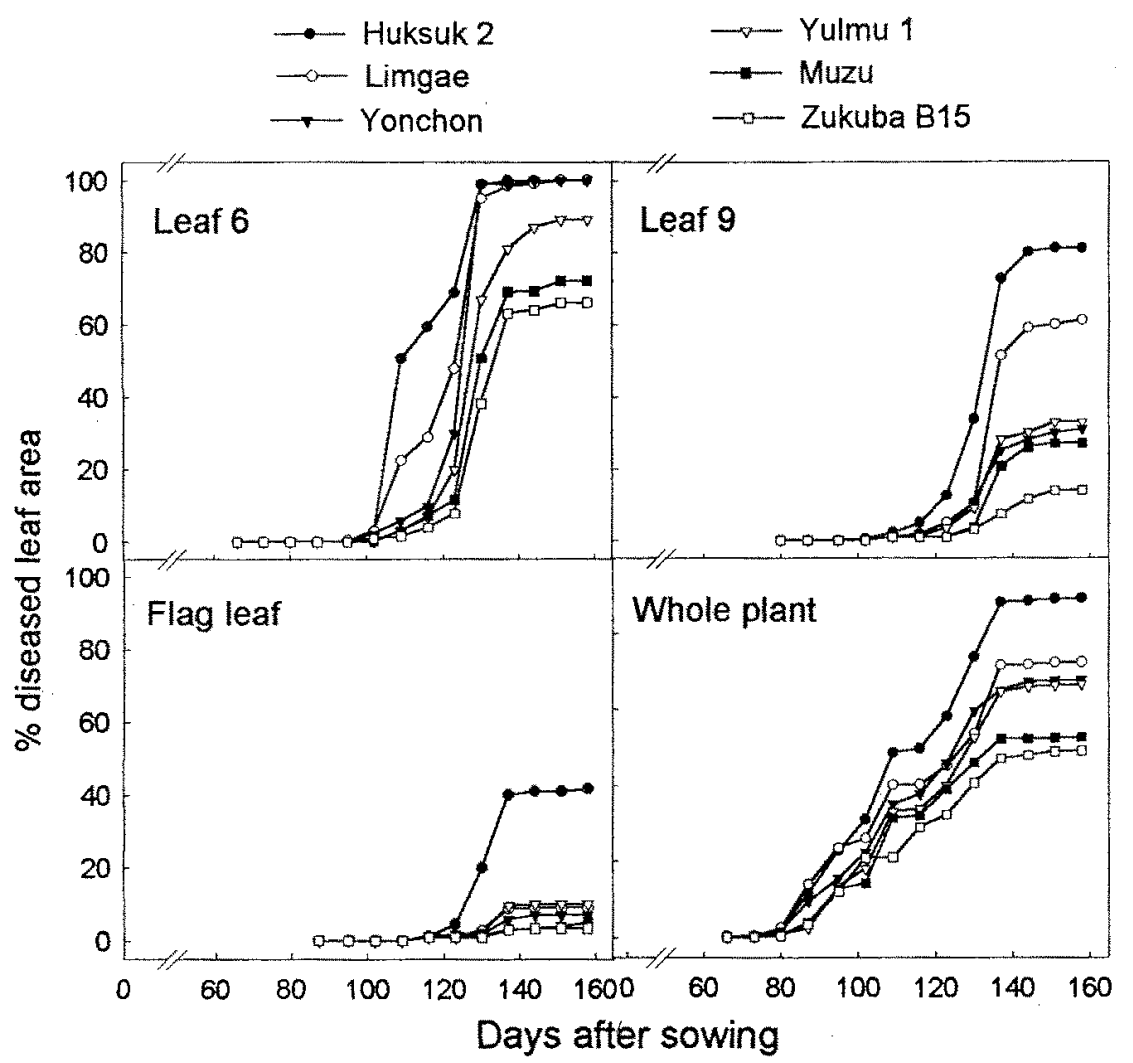

Fig. 1. Disease progress curves of adlay leaf blight on different leaves and whole plants for six adlay genotypes (Tsukuba B 15 and Muzu: resistant; Yulmu 1 and Yonchon: moderately resistant; Limgae and Huksuk 2: susceptible) representing different levels of resistance to Bipolaris coicis in the hill plots sown on 17 April 1997 at Yonchon, Korea. Day $60=16$ June. Leaves are numbered from the ground (leaf 1) up to the flag leaf.

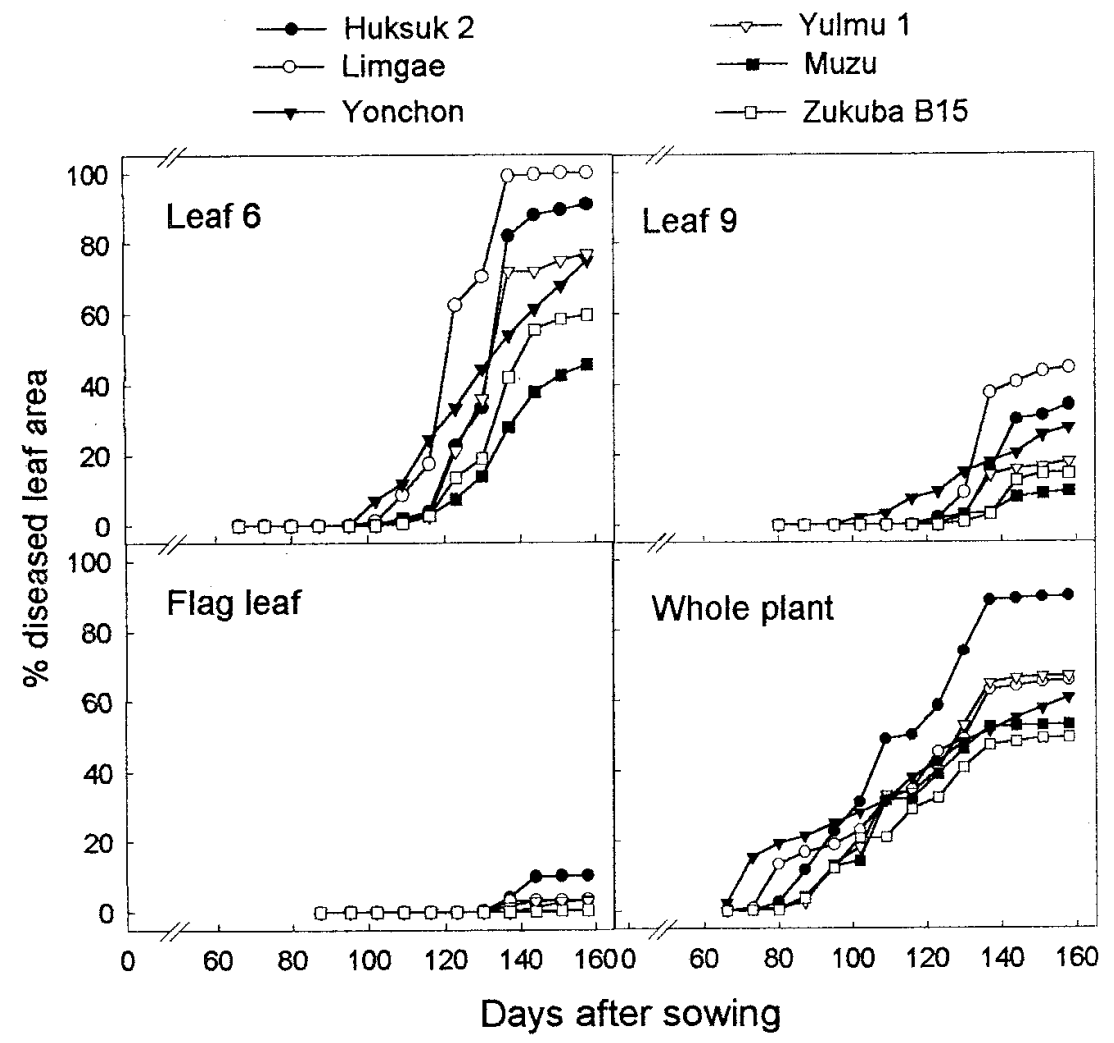

Fig. 2. Disease progress curves of adlay leaf blight in different leaves and whole plants for six adlay genotypes (Tsukuba B 15 and Muzu: resistant; Yulmu 1 and Yonchon: moderately resistant; Limgae and Huksuk 2: susceptible) representing different levels of resistance to Bipolaris coicis in the hill plots sown on 17 April 1998 at Yonchon, Korea. Day $60=16$ June. Leaves are numbered from the ground (leaf 1) up to the flag leaf. relative levels of resistance of adlay genotypes to leaf blight in the field.

At harvest maturity of adlay, grain yield, thousand kernel weight, number of kernels per plant, and percent kernel ripeness were determined. Grain yield was measured from 45 hand-harvested plants from each plot on 2 October 1998 and 3 October 1999. Kernel moisture was adjusted to $12 \%$ by drying the kernels in an aircirculation chamber at $50 \pm 3^{\circ} \mathrm{C}$ for $48 \mathrm{~h}$ prior to measurement. Losses of grain yield and yield components were calculated for each cultivar-nonprotected treatment by comparison with the appropriate protected control. Yield components such as kernels per plant, percent kernel ripeness, and thousand kernel weight, except grain yield, were estimated by determining the means of three samples per plot. Differences among genotypes were compared using Fisher's protected least significant difference (LSD) test at $P=0.05$. Linear regression analyses were also used to evaluate relationships between terminal disease severity and yield components. SAS (SAS Institute, Cary, NC) was used for all statistical analyses.

\section{RESULTS}

Evaluation of resistance in hill plots. Leaf blight severities and AUDPCs for 30 adlay genotypes varied greatly (Table 1). The development of leaf blight was rapid and severe on lines Huksuk 2, Huksuk 1, and Limgae in 1997. Leaf blight severity remained at relatively low levels on Tsukuba B15, Ou 1, Tsukuba B4, and Muzu throughout the entire growing season. Terminal severities on 158 days after sowing were significantly lower for Tsukuba B15 and Muzu than on those of the highly susceptible cultivars. In contrast, the terminal severity of leaf blight on Huksuk 2 reached over $89 \%$. AUDPC values for Huksuk 2 were significantly higher than those for Tsukuba B15 and Muzu. Results in 1998 were similar to 1997 results, although disease severities were slightly lower in nearly all genotypes (Table 1). The first symptoms of leaf blight also appeared on the lower leaves from 70 to 80 days after sowing. Relative AUDPC levels among adlay genotypes were also similar during both years. AUDPC values were lowest on Tsukuba B7, Tsukuba B15, and Muzu for the entire growing season in 1998, but highest on Huksuk 1, Milyang 4, and Huksuk 2. The AUDPC values reached over 500.6 on Huksuk 1, but only 295.2 on the resistant line Tsukuba B7.

Lower adlay leaves were in general more severely infected than were upper leaves (Table 2). In the 1997 experiment, disease severity remained low only on the line Tsukuba B15 throughout the observation period (Fig. 1). Disease severities on the third leaves were similarly high on the lines Huksuk 2, Limgae, and Yonchon, as indicated by the AUDPC values (Table 2). 
On the sixth leaf, genotypes Huksuk 2, Limgae, Yonchon, and Yulmu 1, showing similar levels of leaf blight as on the third leaves, were quite distinguishable from each other with regard to disease severity. Less disease developed on the ninth leaf on all genotypes tested than on the sixth leaf. Flag leaves were consistently less diseased on all genotypes tested except Huksuk 2. Leaf blight rapidly progressed from 120 to 140 days after sowing, but remained at a constant level 140 days after sowing. Leaf blight progress in 1998 was similar to that of the 1997 sowing (Figs. 1 and 2). Similar trends were found in the AUDPC values during both experiment years (Table 2). AUDPC values were highest on the lower leaves, decreasing with leaf height. However, AUDPC levels varied among the six adlay genotypes. Rankings of adlay genotypes by AUDPC and disease severity values were similar to one another in both years and were in descending order: Tsukuba B15, Muzu, Yulmu 1, Yonchon, Limgae, and Huksuk 2.

Effects of resistance on leaf blight development and adlay yield in the field. In 1998, leaf blight developed rapidly on adlay plants from 120 to 150 days after sowing (Fig. 3). Development of adlay leaf blight during 1999 was lower when compared with the 1998 experiment. In both years, there were visual differences in leaf blight progression on the six adlay genotypes tested. Rates of disease progress in ascending order were Tsukuba B15, Muzu, Yulmu 1, Yonchon, Limgae, and Huksuk 2.

AUDPC values were significantly different among the six adlay genotypes in 1998 and 1999 (Table 3). The highest AUDPC values were obtained from Huksuk 2, followed by Yonchon, Yulmu 1, Limgae, Muzu, and Tsukuba B15. Compared with those in fungicide-sprayed plots, adlay yields in plots naturally infected by leaf blight were 28.5 to $52.4 \%$ lower in the 1998 experiment, depending on the level of host resistance (Table 3). Huksuk 2 showed the greatest yield loss, followed by Yulmu 1, Limgae, Yonchon, Muzu, and Tsukuba B15. During 1999, grain yields were reduced by 9.3 to $44.7 \%$ by leaf blight infection in 1999, compared with those of disease-free plots. The levels of yield loss in the infected plots were similar to those of 1998 , with greatest losses in Huksuk 2 and lowest losses in Tsukuba B15.

Leaf blight was more severe in 1998 than in 1999, and reductions in individual yield components were correspondingly greater in 1998 (Table 4). Kernel numbers per plant in 1998 showed a trend similar to total grain yield, with losses of 7.9 to $23.8 \%$ across genotypes. There were also significant differences in percent kernel ripeness among adlay genotypes. In the 1998 experiment, thousand kernel weight losses ranged from $8.6 \%$ in Tsukuba B15

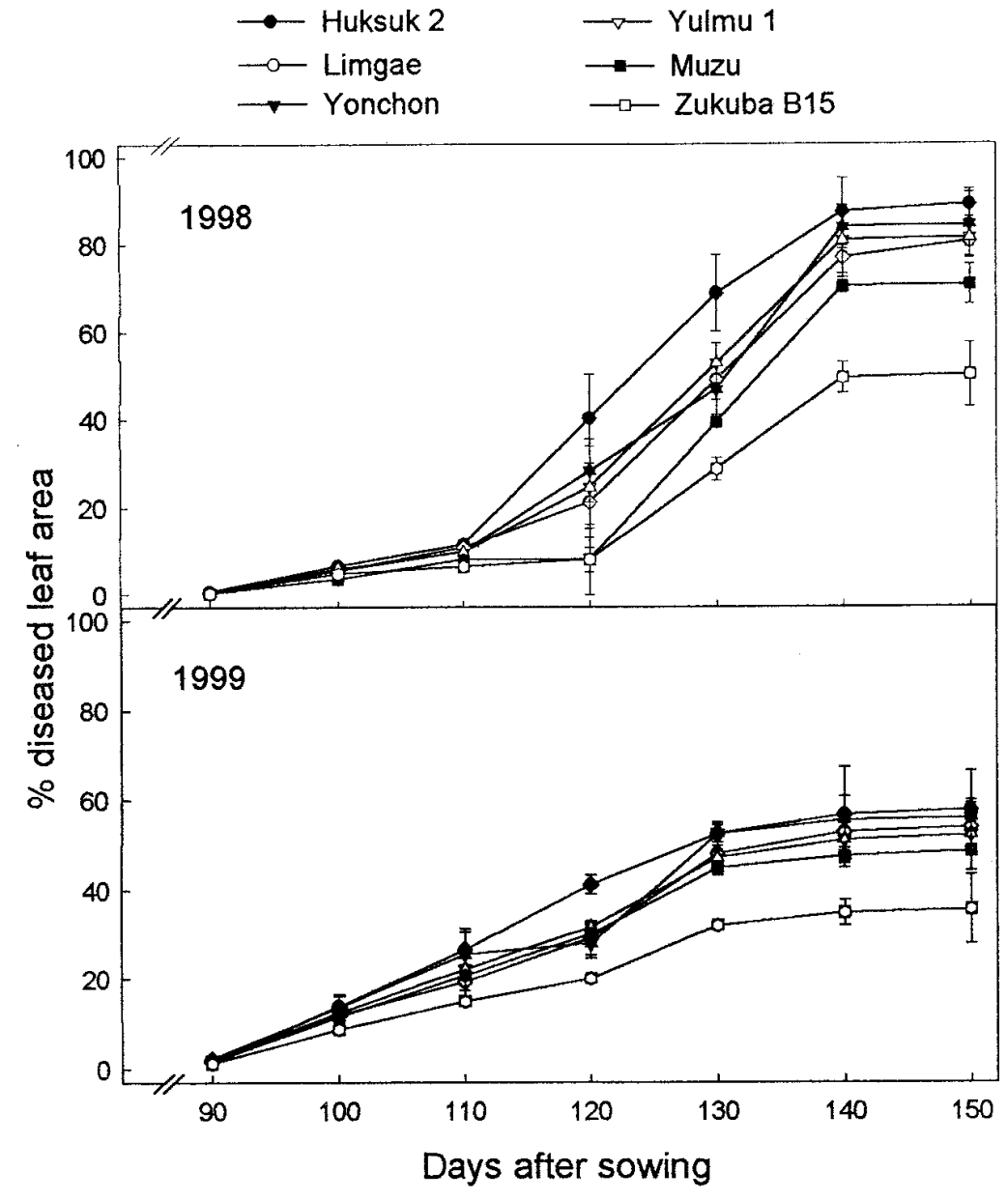

Fig. 3. Disease progress curves of leaf blight for six adlay genotypes (Tsukuba B 15 and Muzu: resistant; Yulmu 1 and Yonchon: moderately resistant; Limgae and Huksuk 2: susceptible) representing different levels of resistance to Bipolaris coicis in the field plots for assessment of yield potentials, sown on 17 April 1998 and 1999 at Yonchon, Korea.

Table 3. Area under disease progress curve (AUDPC) for leaf blight and yield and yield losses for six adlay genotypes naturally infected with Bipolaris coicis in the field plots sown on 17 April 1998 and 1999 at Yonchon, Korea

\begin{tabular}{|c|c|c|c|c|c|}
\hline \multirow[b]{2}{*}{ Genotype } & \multicolumn{2}{|c|}{ AUDPC } & \multicolumn{3}{|c|}{ Yield (kg/ha) } \\
\hline & Untreated $^{\mathrm{x}}$ & Treated $^{y}$ & Untreated & Treated & Loss $(\%)$ \\
\hline \multicolumn{6}{|l|}{1998} \\
\hline Huksuk 2 & $259.9 \mathrm{a}^{\mathrm{z}}$ & $23.1 \mathrm{a}$ & 1,960 & 4,116 & $52.4 \mathrm{a}$ \\
\hline Limgae & $204.4 \mathrm{ab}$ & $27.0 \mathrm{a}$ & 2,124 & 3,893 & $45.4 \mathrm{bc}$ \\
\hline Yonchon & $217.3 \mathrm{ab}$ & $22.3 \mathrm{a}$ & 2,291 & 3,925 & $41.6 \mathrm{c}$ \\
\hline Yulmu 1 & $215.6 \mathrm{ab}$ & $20.8 \mathrm{a}$ & 2,314 & 4,520 & $48.8 \mathrm{~b}$ \\
\hline Muzu & $165.1 \mathrm{bc}$ & $23.0 \mathrm{a}$ & 3,026 & 4,849 & $37.6 \mathrm{~cd}$ \\
\hline Tsukuba B15 & $120.9 \mathrm{c}$ & $15.7 \mathrm{~b}$ & 2,605 & 3,643 & $28.5 \mathrm{~d}$ \\
\hline $\mathrm{LSD}_{0.05}$ & 9.0 & 0.7 & $\ldots$ & $\ldots$ & 4.3 \\
\hline \multicolumn{6}{|l|}{1999} \\
\hline Huksuk 2 & $221.8 \mathrm{a}$ & $8.7 \mathrm{a}$ & 2,306 & 4,172 & $44.7 \mathrm{a}$ \\
\hline Limgae & $190.8 \mathrm{bc}$ & $8.7 \mathrm{a}$ & 2,759 & 3,991 & $30.9 \mathrm{~b}$ \\
\hline Yonchon & $205.7 \mathrm{~b}$ & $8.7 \mathrm{a}$ & 3,184 & 4,462 & $28.6 \mathrm{bc}$ \\
\hline Yulmu 1 & $193.2 b c$ & $8.8 \mathrm{a}$ & 3,167 & 4,770 & $33.6 \mathrm{~b}$ \\
\hline Muzu & $178.3 \mathrm{c}$ & $9.0 \mathrm{a}$ & 3,351 & 4,721 & $29.1 \mathrm{bc}$ \\
\hline Tsukuba B15 & $132.0 \mathrm{~d}$ & $8.4 \mathrm{a}$ & 3,610 & 3,979 & $9.3 \mathrm{c}$ \\
\hline $\mathrm{LSD}_{0.05}$ & 9.7 & 0.8 & $\ldots$ & $\ldots$ & 5.2 \\
\hline
\end{tabular}

${ }^{\mathrm{x}}$ Nonsprayed control plots.

y Difenoconazole-sprayed plots. These plots were completely protected from leaf blight by spraying fungicide every 10 days from just before heading to harvest.

${ }^{\mathrm{z}}$ Values in each column with different letters show significant differences at $P=0.05$ according to the Fisher's protected least significant difference (LSD) test. 
to $15.0 \%$ in Huksuk 2. Yield components during 1999 showed slightly lower reductions than in 1998, but presented similar trends. The relative ranking of adlay genotypes was generally in agreement, with Tsukuba B15 having the lowest losses and Huksuk 2 having some of the greatest losses in both years.

In the 1998 and 1999 experiments, there was a positive linear relationship between yield or yield component loss and disease severity (\% diseased leaf area) (Fig. 4). Grain yield, kernels per plant, percent kernel ripeness, and thousand kernel weight decreased as disease severity increased. Yield loss varied considerably among adlay genotypes and years. Yield and yield component loss were positively correlated with disease severity values in naturally $B$. coicis-infected plots. Linear regression models explained 70 to $88 \%$ of the variation in losses of yield, kernels per plant, percent kernel ripeness, and thousand kernel weight as a function of disease severity.

\section{DISCUSSION}

The adlay breeding program of the NARS, ARES in Korea has placed a great emphasis on selecting adlay cultivars resistant to leaf blight caused by B. coicis (12). Among 30 important adlay genotypes released between 1997 and 1998, partial resistance to leaf blight was observed. When compared on the basis of disease severity by natural infection, adlay genotypes that were tested displayed a wide range in resistance to leaf blight.

Leaf blight typically appeared first on lower leaves of adlay and spread to leaves in the middle and upper portions of the canopy in late June. This may be because lower leaves are usually the site of primary infection in the developing canopy. Subsequently, under favorable environmental conditions, B. coicis conidia formed on the lesions by initial infections are disseminated to the upper leaves of adlay. By the later stages of crop development, leaf blight was extremely severe in all adlay genotypes tested (Table 1).
Leaf blight progresses more rapidly when frequent and prolonged periods of high relative humidity are favorable for pathogen reproduction. Moreover, since most of the adlay cultivars presently cultivated in Korea were highly or moderately

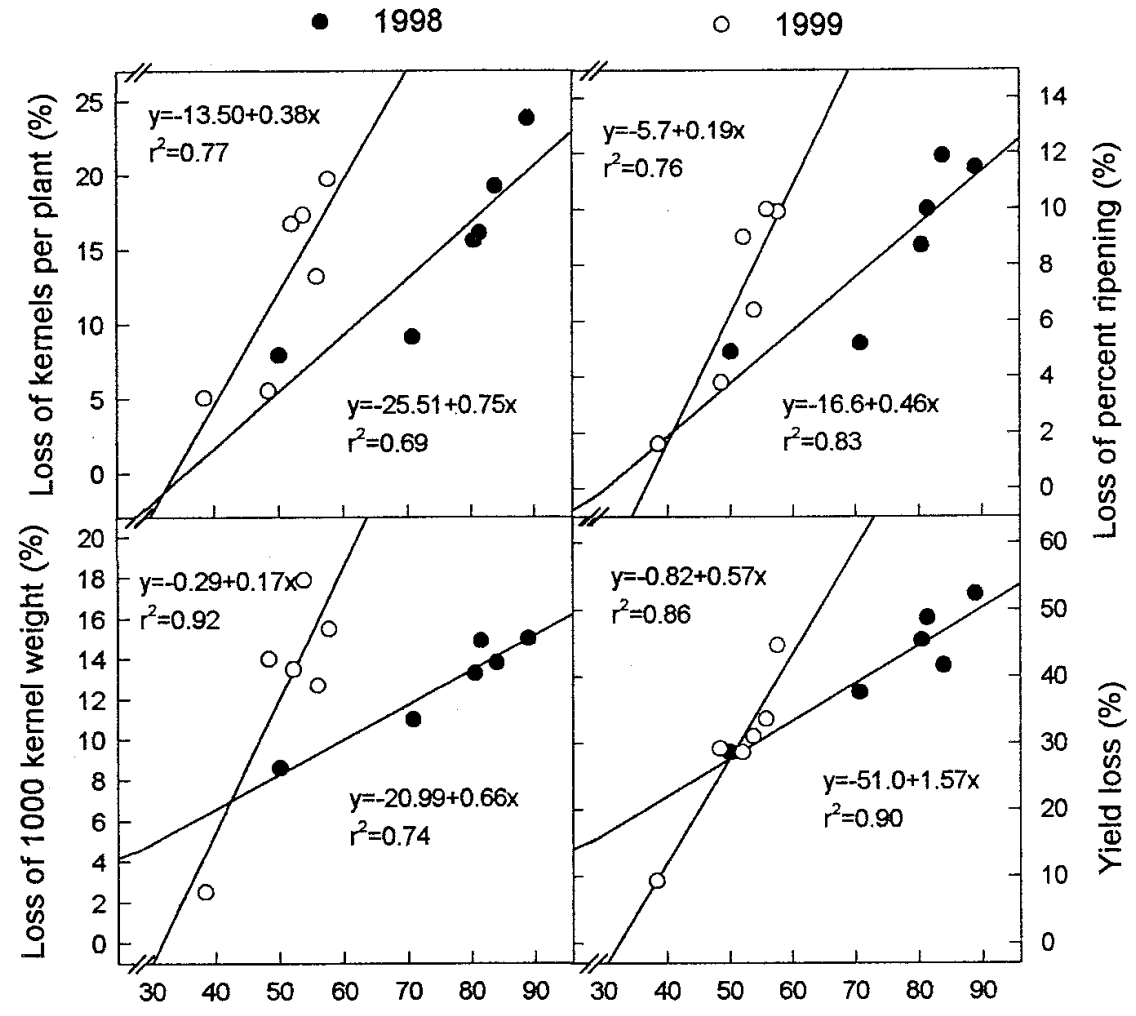

\section{Disease severity}

Fig. 4. Linear regressions of losses of adlay yield and yield components on disease severities (\% diseased leaf area) of leaf blight for six genotypes (Tsukuba B 15 and Muzu: resistant; Yulmu 1 and Yonchon: moderately resistant; Limgae and Huksuk 2: susceptible) grown in 1998 and 1999 at Yonchon, Korea. Disease severity data were evaluated 158 days after sowing.

Table 4. Yield components and losses for six adlay genotypes naturally infected with Bipolaris coicis in the field plots sown on 17 April 1998 and 1999 at Yonchon, Korea

\begin{tabular}{|c|c|c|c|c|c|c|c|c|c|}
\hline \multirow[b]{2}{*}{ Genotype } & \multicolumn{3}{|c|}{ Kernels per plant } & \multicolumn{3}{|c|}{ Percent kernel ripeness } & \multicolumn{3}{|c|}{ Thousand kernel weight (g) } \\
\hline & $\mathbf{U}^{\mathrm{x}}$ & $\mathbf{T}^{\mathbf{y}}$ & Loss (\%) & $\mathbf{U}$ & $\mathbf{T}$ & $\operatorname{Loss}(\%)$ & $\mathbf{U}$ & $\mathbf{T}$ & $\operatorname{Loss}(\%)$ \\
\hline \multicolumn{10}{|l|}{1998} \\
\hline Huksuk 2 & 351.1 & 461.2 & $23.8 \mathrm{a}^{\mathrm{z}}$ & 71.7 & 81.0 & $11.5 \mathrm{a}$ & 102 & 120 & $15.0 \mathrm{a}$ \\
\hline Limgae & 347.9 & 412.1 & $15.6 \mathrm{~b}$ & 67.3 & 73.7 & $8.7 \mathrm{~b}$ & 91 & 105 & $13.3 \mathrm{a}$ \\
\hline Yonchon & 363.6 & 450.0 & $19.2 \mathrm{ab}$ & 78.5 & 89.1 & $11.9 \mathrm{a}$ & 94 & 109 & $13.8 \mathrm{a}$ \\
\hline Yulmu 1 & 370.8 & 441.7 & $16.1 \mathrm{~b}$ & 75.6 & 84.0 & $10.0 \mathrm{a}$ & 86 & 101 & $14.9 \mathrm{a}$ \\
\hline Muzu & 389.2 & 428.2 & $9.1 \mathrm{bc}$ & 79.7 & 84.1 & $5.2 \mathrm{c}$ & 105 & 118 & $11.0 \mathrm{~b}$ \\
\hline Tsukuba B15 & 372.6 & 404.5 & $7.9 \mathrm{c}$ & 81.3 & 85.5 & $4.9 \mathrm{c}$ & 127 & 139 & $8.6 \mathrm{~b}$ \\
\hline $\mathrm{LSD}_{0.05}$ & $\cdots$ & $\ldots$ & 6.5 & $\ldots$ & $\ldots$ & 3.5 & $\ldots$ & $\ldots$ & 1.9 \\
\hline \multicolumn{10}{|l|}{1999} \\
\hline Huksuk 2 & 383.9 & 477.9 & $19.7 \mathrm{a}$ & 70.1 & 77.8 & $9.9 \mathrm{a}$ & 98 & 116 & $15.5 \mathrm{ab}$ \\
\hline Limgae & 361.4 & 437.0 & $17.3 \mathrm{ab}$ & 73.5 & 78.5 & $6.4 \mathrm{~b}$ & 87 & 106 & $17.9 \mathrm{a}$ \\
\hline Yonchon & 387.0 & 464.8 & $16.7 \mathrm{ab}$ & 68.7 & 75.5 & $9.0 \mathrm{ab}$ & 96 & 111 & $13.5 \mathrm{~b}$ \\
\hline Yulmu 1 & 390.9 & 450.5 & $13.2 \mathrm{~b}$ & 69.4 & 77.1 & $10.0 \mathrm{a}$ & 89 & 102 & $12.7 \mathrm{~b}$ \\
\hline Muzu & 410.3 & 434.3 & $5.5 \mathrm{c}$ & 76.9 & 79.9 & $3.8 \mathrm{c}$ & 98 & 114 & $14.0 \mathrm{~b}$ \\
\hline Tsukuba B15 & 404.1 & 425.5 & $4.9 \mathrm{c}$ & 75.5 & 76.7 & $1.6 \mathrm{~d}$ & 117 & 120 & $2.2 \mathrm{c}$ \\
\hline $\mathrm{LSD}_{0.05}$ & $\ldots$ & $\ldots$ & 3.9 & $\ldots$ & $\ldots$ & 1.6 & $\ldots$ & $\ldots$ & 2.2 \\
\hline
\end{tabular}

${ }^{\mathrm{x}}$ Nonsprayed control plots.

y Difenoconazole-sprayed plots. These plots were completely protected from leaf blight by spraying fungicide every 10 days from just before heading to harvest.

${ }^{\text {z }}$ Values in each column with different letters show significant differences at $P=0.05$ according to the Fisher's protected least significant difference (LSD) test. 
susceptible to $B$. coicis, growing these cultivars may not be effective in reducing the development of leaf blight in the field. More frequent and heavier rains in 1997 than in 1998 may have accounted for the more severe epidemic of leaf blight. Significant differences in disease severity among adlay genotypes were observed in both 1997 and 1998 (Tables 1).

Leaf position in adlay plants had a significant influence on leaf blight severity, which was greatest on the lowest leaf and decreased on each successively higher leaf. For instance, the AUDPCs for the third, sixth, ninth, and flag leaves of Huksuk 2 in 1998 were 818.7, 400.6, 95.3, and 27.7, respectively, which were significantly different from one another (Table 2). While there is little information in the literature about leaf blight development as influenced by leaf position, our observations revealed that leaves of all adlay genotypes, both resistant and susceptible, appeared to become increasingly susceptible to leaf blight as leaves age. This phenomenon has also been observed in other plant-pathogen systems $(6,14)$. The increased susceptibility of wheat to tan spot, caused by Pyrenophora tritici-repentis, with leaf aging was found by Raymond et al. (16). They showed that older leaves of wheat had higher disease ratings than younger leaves, despite being inoculated at the same time. Watkins et al. (24) also observed that coalescence of tan spot lesions occurred on lower (older) leaves of wheat, but lesions on upper (younger) leaves appeared restricted.

Epidemics of leaf blight were shown to develop rapidly in some adlay genotypes, which significantly reduced grain yield. Although it was apparent that certain adlay cultivars possessed some degree of resistance to leaf blight, none of the adlay genotypes tested exhibited complete resistance. The relative levels of resistance of six adlay genotypes to leaf blight observed in the field plots were very similar to those observed in earlier hill plot tests (Table 2). Huksuk 2 was highly susceptible to leaf blight, and the resistant line Tsukuba B15 showed significantly lower disease severities than the other cultivars or lines tested. Yonchon and Yulmu 1 were moderately susceptible to leaf blight in the field.

During the 1998 and 1999 field experiments, adlay yield loss was largely attributed to the negative effect of leaf blight on the number of kernels per plant, percent kernel ripeness, and thousand kernel weight. The three yield components are considered the most important factors in adlay production. However, it had not been known which yield component is affected by leaf blight. Based on the results obtained in our study, yield and yield component loss were positively correlated with disease severity (Fig. 4). Differences in total yield loss and yield component losses varied greatly among adlay genotypes. As severity of adlay leaf blight increased, grain yield and yield components decreased in the 2-year field trials. The line Tsukuba B15, which was resistant to leaf blight, showed a more stable yield potential than the other tested adlay genotypes. Differences in yield and yield component loss among cultivars have readily been found in other crops $(15,20)$. Sharp et al. (20) reported about $20 \%$ losses in grain yield by tan spot in winter wheat. The disease was observed to cause 9 to $20 \%$ reduction in thousand kernel weight in seven of 30 cultivars of spring wheat. Steffenson et al. (22) demonstrated that susceptible barley cultivar Kombar showed yield losses of 31 to $35 \%$ by Pyrenophora teres $\mathrm{f}$. sp. teres infection, chiefly due to a reduction in thousand kernel weight. In adlay, however, each of the yield components measured appeared to be equally important in contributing to final yield loss, as confirmed by our field studies.

Cultivation of resistant cultivars may be practical as a form of adlay leaf blight management, although use of fungicides can be more effective in reducing leaf blight severity. In particular, adlay line Tsukuba B15, which has a partial resistance to $B$. coicis, would be valuable for cultivation or for use as a parent in an adlay resistance breeding program.

\section{LITERATURE CITED}

1. Arora, R. K. 1977. Job's tears (Coix lacrymajobi) - a minor food and fodder crop from northeastern India. Econ. Bot. 31:358-366.

2. Chang, S. W., and Hwang, B. K. 1999. Field evaluation of adlay cultivars or lines for resistance to leaf blight caused by Bipolaris coicis. (Abstr.) Plant Pathol. J. 15:182.

3. Chang, S. W., Kim, H. D., and Jeon, D. H. 2000. Effects of seed disinfectant treatments on leaf blight and smut disease in Coix lachryma-jobi L var. ma-yuen STAPF. Korean J. Medicinal Crop Sci. 8:79-82.

4. Fried, P. M., Mackenzie, D. R., and Nelson, R. R. 1981. Yield loss caused by Erysiphe graminis f. sp. tritici on single culms of "Chancellor" wheat and for multilines. Z. Pflanzenkrankh. Pflanzenschutz 88:256-264.

5. Honkura, R., Oikawa, T., and Inoue, T. 1982. Studies on diseases of Job's tears I. Influence of cultivation method on occurrence of Job's tears leaf blight. Annu. Rep. Soc. Plant Prot. N. Jpn. 33:53-54

6. Hosford, R. M., Jr., Jordahl, J. G., and Hammond, J. J. 1990. Effect of wheat genotype, leaf position, growth stage, fungal isolate, and wet period on tan spot lesions. Plant Dis. 74:385-390.
7. Inoue, T., Oikawa, T., and Honkura, R. 1982. Studies on diseases of Job's tears II. Infection source of leaf blight. Annu. Rep. Soc. Plant Prot. N. Jpn. 33:55-57.

8. Jain, S. K., and Banerjee, D. K. 1974. Preliminary observations on the ethnobotany of the genus Coix. Econ. Bot. 28:38-42.

9. Kim, J. S., and Lee, D. H. 1998. Seed transmission of Bipolaris coicis, B. cynodontis, $B$. maydis and Curvularia lunata causing leaf blight of job's tears. Korean J. Plant Pathol. 14:287-293.

10. Kim, S. K., Kim, K. W., Hong, S. S., Park, E. W., Yang, J. S., and Kim, Y. J. 1997. Isolation and identification of Bipolaris coicis, causing leaf blight of job's tears. Korean J. Mycol. 25:291-296.

11. Large, E., and Doling, D. A. 1983. Effect of mildew on yield of winter wheat. Plant Pathol. 12:128-130.

12. Lee, H. S., Park, K. J., Kim, K. J., and Yi, E. S. 1997. Effects of field topography, ridge shape and crop rotation on growth and yield in Coix lachyma var. ma-yuen Stapf. Korean J. Medicinal Crop Sci. 5:162-166.

13. Luttrell, E. S. 1969. Curvularia coicis and the nodulosa group of Bipolaris. Mycologia 61:1031-1040.

14. Nutter, F. W, Pederson, V. D., Jr., and Foster, A. E. 1985. Effect of inoculations with Cochliobolus sativus at specific growth stages on grain yield and quality of malting barley. Crop Sci. 25:933-938.

15. Pataky, J. K., Raid, R. N., du Toit, L. J., and Schueneman, T. J. 1998. Disease severity and yield of sweet corn hybrids with resistance to northern leaf blight. Plant Dis. 82:57-63.

16. Raymond, P. J., Bockus, W. W., and Norman, B. L. 1985. Tan spot of winter wheat: Procedures to determine host response. Phytopathology 75:686-690.

17. Rees, R. G., Platz, G. J., and Mayere, R. J. 1982. Yield losses in wheat from yellow spot: Comparison of estimates derived from single tillers and plots. Aust. J. Agric. Res. 33:899908.

18. Schaaffhausen, R. V. 1952. Adlay or Job's tears a cereal of potentially greater economic importance. Econ. Bot. 6:216-227.

19. Shaner, G., and Finney, R. E. 1977. The effect of nitrogen fertilization on the expression of slow mildewing resistance in Knox wheat. Phytopathology 67:1051-1056.

20. Sharp, E. L., Sally, B. K., and McNeal, F. H. 1976. Effects of Pyrenophora wheat leaf blight on the thousand kernel weight of 30 spring wheat cultivars. Plant Dis. Rep. 60:135-138.

21. Sivanesan, A. 1987. Graminoclolus Bipolaris, Curvularia, Drechslera, Exserohilum, and their telemorph. Mycological Papers. CAB International Mycological Institute, Surrey, England. pp. 54-55.

22. Steffenson, B. J., Webster, R. K., and Jackson, L. F. 1991. Reduction in yield loss using incomplete resistance to Pyrenophora teres $\mathrm{f}$. teres in barley. Plant Dis. 75:96-100.

23. Tsuda, M., and Ueyama, A. 1977. Pseudocochliobolus nisikadoi, the perfect state of Helminthosporium coicis. Mycologia 69:1109-1120.

24. Watkins, J. E., Odvody, G. N., Boosalis, M. G., and Partridge, J. E. 1978. An epidemic of tan spot of wheat in Nebraska. Plant Dis. Rep. 62:132-134. 